\title{
Initiatives in Astronomy Education in South Africa
}

\author{
Case L. Rijsdijk
}

South African Astronomical Observatory, PO Box 9, Observatory, 7935, South Africa. e-mail: case@saao.ac.za

\begin{abstract}
A brief review of the issues affecting the current status of science education in general, and astronomy education in particular, is given. The paper looks at the present situation at primary, secondary and tertiary levels. South Africa has unique educational problems and the initiatives by local observatories and universities at school level are described. The problems encountered by the South African Astronomical Observatory (SAAO) Science Education Initiative (SEI) are typical, as is the SEI approach to addressing some of these. The experience of the SEI is described, as are some of the resources developed by them for primary and secondary schools. Finally a brief look is taken at future developments, in particular, ways in which the Southern African Large Telescope (SALT) can contribute to astronomy and science education.
\end{abstract}

\section{Background}

The history leading up to the present crisis in South African education in general, and science education in particular, is well documented (Blankley 1994, Medupe and Kaunda 1997). Since 1994 several people (Grayson 1996, 1997, Rutherford 1997) at the tertiary level have suggested and tried models to address some of these problems.

\section{Problems}

For learners at South African schools the problems in science education start with under-qualified and unqualified science teachers: only $16 \%$ of science teachers in the country have one or more years of a science subject at university (Arnott and Kubheka 1996). Of the remaining $84 \%$ many are teaching learners ${ }^{1}$ at $a$ level that they themselves have not achieved! It is not unusual for a teacher who left school with a grade-10 certificate now to be teaching grade-12

\footnotetext{
${ }^{1}$ Because many students in South Africa are older than their peers, especially in the lower grades, and because many people are entering formal education as adults, pupils and students are often referred to as learners.
} 

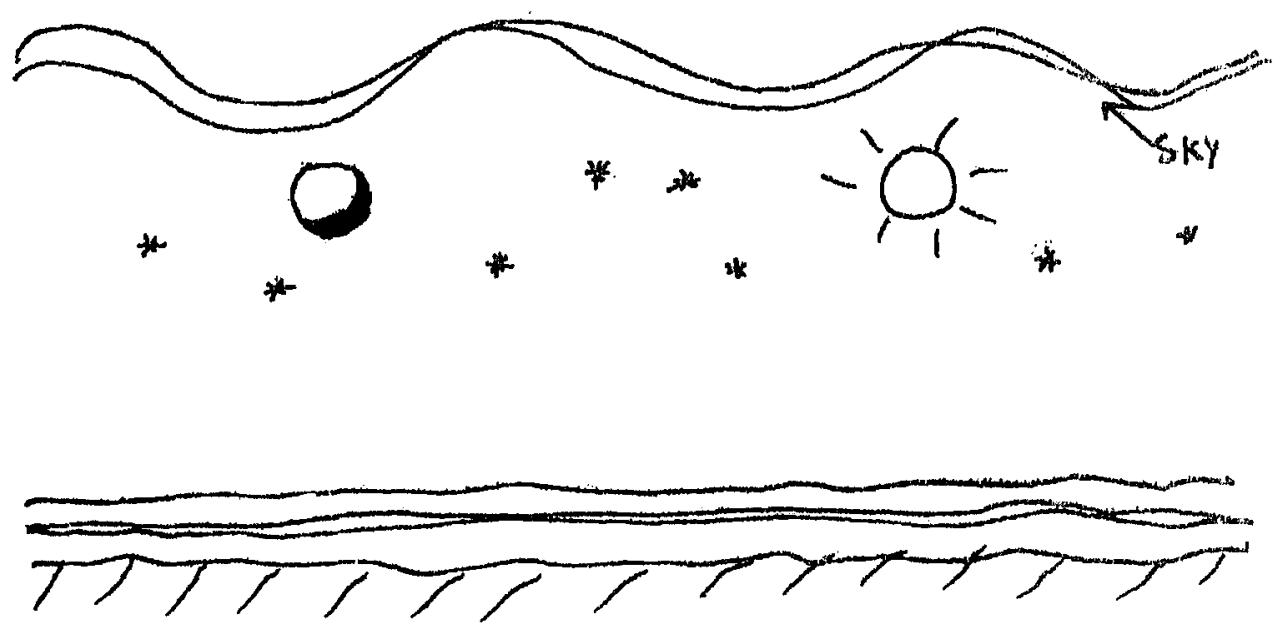

Figure 1. Flat Earth...

learners. In many cases, especially among the black teachers, the science subject studied is biology and it is these teachers who are expected to teach physics and chemistry as well. Many have had little or no exposure to physics or chemistry other than that which they picked up at school or in their studies of biology.

Before 1996 astronomy was taught only as a small section of the geography syllabus as an introduction to the Earth's geography. It started by looking at a very simplistic portrayal of the "Big Bang", as a rationale for the existence of matter out of which the solar nebula formed, followed by the formation of the solar system and ended by looking at the Earth's place in the solar system/universe. Textbooks were frequently written in the northern hemisphere and so the Moon's phases were wrong: just full, new and quarter were shown to try to offer some sort of explanation for the tides! Eclipses were sometimes covered in physics as an example of "rectilinear propagation of light": an explanation was seldom offered for the causes of the Moon's phases or why there was no eclipse every month. In fact this section was usually omitted for two reasons: it was NEP (not for examination purposes) and, more commonly, the teacher knew very little, if any astronomy: frequently misconceptions were perpetuated, (see below).

Many of our black children do not live in an environment that is conducive to learning or science. Their parents had minimal if any schooling, are illiterate and as a result there are no books, magazines or newspapers in the home. Overcrowding within the home is also a problem in that children have little or no space in which to try to do homework and many need to get jobs to help the family survive.

At school many of these children are not much better off, resources at schools are poor and very limited: many do not have electricity let alone a phone line. In addition classrooms are overcrowded, teachers often have to cope with classes that have $60+$ learners in them. 


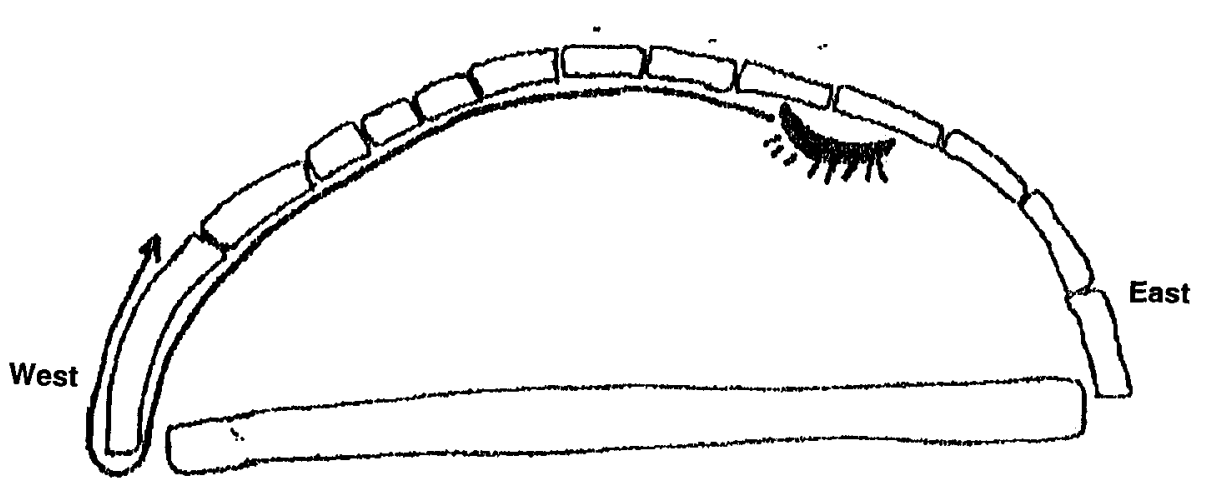

Can account for the occurrence of day, night, stars.

Figure 2. Geocentric Flat Earth. Conflict between untutored views and scientific views!

Added to the above is the language problem: South Africa has 11 official languages and many dialects. These languages were oral, only formalized and given a linguistic structure relatively recently and use a Western alphabet. Since these written languages are new, their vocabulary has not yet developed properly and often one word is used to describe several phenomena. This becomes particularly critical when scientific words with precise meanings are used. In one local language for example the word "amandla" can be used to describe "energy", "force" and "power": learners understandably become confused.

At high-school and university levels, instruction is often given in a language other than the learners' or students' mother tongue. ${ }^{2}$ Ongoing research (Clerk, 2000) with first-year university students seems to indicate that students benefit from conversation with instructors, both on and off the topic: something that didn't happen at school.

\section{Prior Knowledge and Misconceptions}

It is well known that there are many misconceptions about even the simplest astronomical and scientific phenomena. Many people do not really understand how the phases of the Moon occur, or why seasons happen (Schneps and Sadler 1988). Many teachers in South Africa have these and other misconceptions. Research carried out at Potchefstroom University (Wesi, Lemmer and Smit 2000) on a group of local teachers, who were asked to make a sketch of their view of the universe, produced some interesting representations :

Many showed other interesting features, and some common ideas were observed, amongst which were:

- a flat Earth with the sky beyond the Sun, Moon and stars,

\footnotetext{
'I will continue to use the term "students" for those in tertiary institutions.
} 


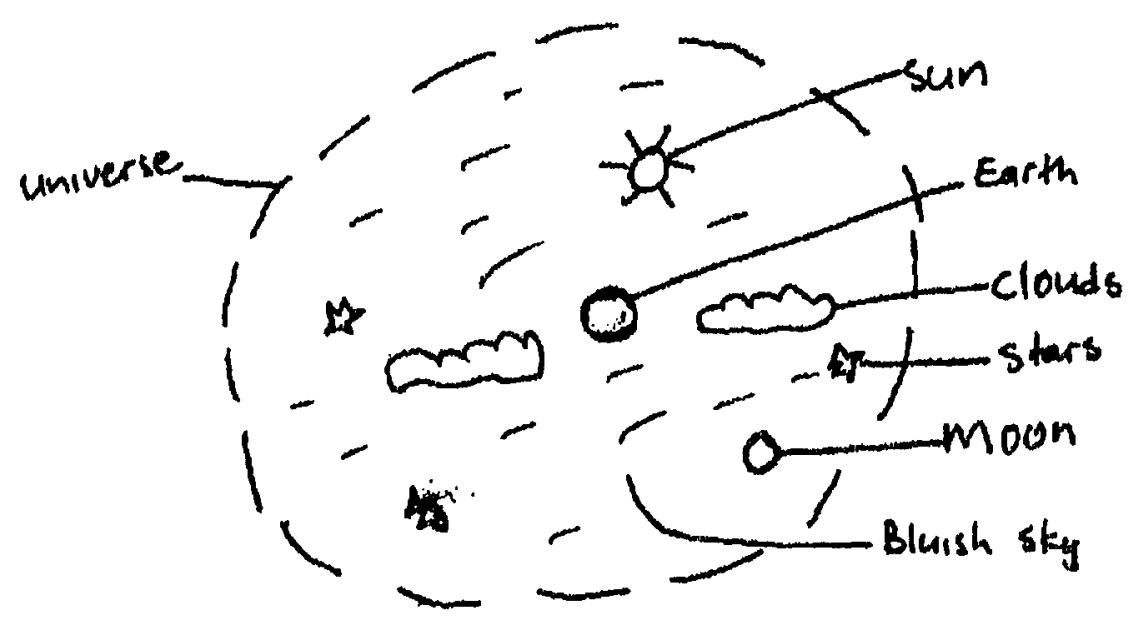

Figure 3. Random Universe: spherical and bounded universe.

- living things such as trees, animals and people on a flat Earth,

- often the crescent Moon and Sun were in such a position that the dark side was illuminated.

When one talks to students after a workshop or slide presentation it becomes clear that many still see the Sun as a small bright object moving across and above the plane of a flat, stationary Earth and that the phases of the Moon are caused by the Earth's shadow.

Because of the impoverished background of many learners, a lot of concepts, examples and material are "learnt" but often not understood: learners are unable to see how and where to apply the knowledge gained. Assessment might show that students "know" their physics yet struggle to apply it to solve problems: their misconceptions are often complex and deep-rooted (Enderstein and Spargo 1998).

Teachers frequently stifle questioning for fear of having their own lack of knowledge exposed or to save themselves from embarrassment when learners ask questions of a speaker the teacher thinks are stupid. On one occasion a learner was reprimanded for asking what his teacher thought to be a stupid question: she intervened by saying ". . . everyone knows those dark patches on the Moon are shadows caused by clouds!" This after just having painstakingly explained that there was no air (atmosphere) or free water on the Moon!

\section{Addressing the Problems}

The efforts by the South African Astronomical Observatory (SAAO) are fairly typical of the approach adopted by the astronomical community in South Africa. The Science Education Initiative (SEI) at SAAO realized that there was little point in teaching astronomy to a population that had little or no science. It therefore adopted the approach to use astronomy as a vehicle for science education, (Rijsdijk, 2000): at least until such time that the levels of science education 
had reached a stage where some proper astronomy could be profitably taught. There are schools where the levels of education are on a par with, or exceed, their First-World counterparts, and here the SEI was able to support teachers with some proper astronomy education using modern resources such as computers, the Internet and small telescopes.

The SEI identified at an early stage that the target group for its limited resources, both human and financial, were teachers rather than learners. The main reason being that there were just too many learners to interact with profitably: one teacher would be able to share her/his gains with many learners for the rest of his/her teaching career. Later this was narrowed down to those teaching at the upper end of the primary-education levels: grades 5-9, (Rijsdijk, 2000). The main reason being that grade 10-12 teachers were too involved with preparing their learners for the matriculation exams to want to get involved with "new stuff that is not even in the syllabus". This did not mean however that learner groups were excluded: often learner groups provided an ideal testing ground for newly developed materials and resources.

The SEI then focused on two things: developing resources to help teachers and run workshops where they could come to grips with the material and take it into the classroom with confidence. However for this to be practical, the first task was to get astronomy re-introduced into the curriculum. This was achieved in 1996, and since then a wide variety of resources and teacher support material has been developed by the SEI.

The South-African government declared 1998 to be the Year of Science and Technology (YEAST): an ambitious project to promote science and technology throughout the country, with a focus month allocated to each province. In addition the Science Councils were also asked to focus on an area of their speciality: the National Research Foundation (then the Foundation for Research Development) chose Astronomy and Space Science. As a result of this the SAAO developed the "Friends with the Universe" project, (Rijsdijk, 1998). This proved most successful and has been retained as the SAAO outreach programme, more or less replacing the SEI.

\subsection{Resources}

It became clear, as has been mentioned on previous occasions, (Rijsdijk, 1998, 2000), that whatever resources were developed would need to be:

- cheap and simple,

- use readily available materials, i.e. scrap cardboard tubing, paper, wire, marbles etc.,

- easily reproducible,

- of a modular format,

- needed to be relevant/applicable to the local environment,

- focus on group work and skills development,

- supported with activities and assessment material, 
so that after the teachers had themselves worked through the materials in a workshop environment, these resources could be taken straight into the classroom. Teachers were always given some sort of "resource pack" to take away with them: usually this took the form of a set of "how to" notes of the workshop accompanied by exemplars of the materials used that could be photocopied. This approach appears to be in line with thinking elsewhere, (Percy, 1999).

During the last few years, "Friends with the Universe" has developed a large range of workshop modules: some of which are unique to the "Friends with the Universe", whilst others are the evolution of other materials from around the world. Some of these can be downloaded straight into common word-processing packages from the SAAO homepage (http://www.saao.ac.za/education) for those schools or teachers that have access to the Internet. As better techniques are developed for transferring images, further modules will be added to the SAAO homepage. To date over 20 different modules have been tried and proved successful. They vary in difficulty and can be used in different grades, see Table 1. Some modules have not been assigned a grade: teachers are encouraged to decide for themselves which ones are appropriate. Learners from different environments have different needs.

Teachers are also given workshop demonstrations on a wide range of astronomy related topics:

- Why do Balloons Float?,

- Weightlessness,

- Magnetic Braking,

- How Rockets Work

- Modeling Orbits

being typical examples.

In addition to these practical, hands-on exercises, teachers can also borrow posters, books, videos and small telescopes (typically 11.5-cm Newtonian reflectors) to enrich their teaching. In order to borrow a telescope a teacher would normally come to the observatory's Science Education Resources Centre and learn how to set up and use the telescope, after which it can be borrowed for about a week.

As a part of YEAST, "Friends with the Universe" developed a set of ten full colour posters that were to be distributed to the bulk of schools in South Africa. They were a multipurpose set in that they were both decorative and educational. A smaller pamphlet on the solar system was also produced. Both are still available to teachers and learners.

The "Friends with the Universe" has also worked closely with, and advised, several NGEO's in developing resources for Curriculum 2005 and in the preparation of local textbooks, newspaper posters and a wide variety of other hand-outs: newspapers especially are increasingly being used as resources by teachers.

Finally, "Friends with the Universe" uses many local, indigenous and universally available resources to help illustrate scientific principles and concepts: 
Table 1. Some of the Modules developed by "Friends with the Universe"

\begin{tabular}{|c|c|c|c|}
\hline No. & Title & Description & Grades \\
\hline 1 & Where is Up? & $\begin{array}{l}\text { Why people don't fall } \\
\text { fall off the Earth }\end{array}$ & $1-3$ \\
\hline 2 & Making Shadows & $\begin{array}{l}\text { What causes shadows } \\
\text { and how to make them } \\
\text { using simple well-known } \\
\text { objects }\end{array}$ & $2-4$ \\
\hline 3 & $\begin{array}{l}\text { Looking at } \\
\text { the Moon }\end{array}$ & $\begin{array}{l}\text { Simple recording } \\
\text { observing of the } \\
\text { Moon's phases }\end{array}$ & $6-9$ \\
\hline 4 & $\begin{array}{l}\text { Where is } \\
\text { the Moon? }\end{array}$ & $\begin{array}{l}\text { Using sunrise/sunset } \\
\text { tables learners predict } \\
\text { future full/new Moons } \\
\text { and make a model to find } \\
\text { the Moon. }\end{array}$ & $6-12$ \\
\hline 5 & Making Comets & $\begin{array}{l}\text { A teacher demonstration } \\
\text { using dry ice to make a comet }\end{array}$ & teachers \\
\hline 6 & The Seascope & $\begin{array}{l}\text { A device to enable learners } \\
\text { to look under water in rock } \\
\text { pools and rivers }\end{array}$ & $6-12$ \\
\hline 7 & Measuring & $\begin{array}{l}\text { Using different techniques } \\
\text { to measure the area of } \\
\text { irregular shapes }\end{array}$ & $7-9$ \\
\hline 8 & Large Numbers & $\begin{array}{l}\text { Making sense of large numbers } \\
\text { by analogy and by taking a } \\
\text { trip to } \alpha \text { Cen. }\end{array}$ & $6-12$ \\
\hline 9 & Quadrants & $\begin{array}{l}\text { Using scrap material a } \\
\text { simple quadrant is made } \\
\text { to measure heights }\end{array}$ & $5-10$ \\
\hline 10 & $\begin{array}{l}\text { Inverse Square } \\
\text { Law }\end{array}$ & $\begin{array}{l}\text { Using a simple grease-spot } \\
\text { photometer this important } \\
\text { law is verified }\end{array}$ & $10-12$ \\
\hline 11 & $\begin{array}{l}\text { The Power of } \\
\text { the Sun }\end{array}$ & $\begin{array}{l}\text { Using } 10 \text { above, the } \\
\text { power of the Sun is } \\
\text { calculated }\end{array}$ & $10-12$ \\
\hline 12 & $\begin{array}{l}\text { How far is } \\
\text { that star? }\end{array}$ & $\begin{array}{l}\text { Using } 10 \text { and } 11 \text { above } \\
\text { the distance to } \alpha \text { Cen. } \\
\text { is calculated }\end{array}$ & $10-12$ \\
\hline 13 & $\begin{array}{l}\text { Observing the } \\
\text { Sun }\end{array}$ & $\begin{array}{l}\text { Safe methods of looking } \\
\text { at the Sun and explaining } \\
\text { what sunspots are }\end{array}$ & $6-12$ \\
\hline 14 & $\begin{array}{l}\text { Making } \\
\text { telescopes }\end{array}$ & $\begin{array}{l}\text { Using cardboard tubes } \\
\text { and plastic lenses learners } \\
\text { make a telescope for about } \$ 1\end{array}$ & $8-12$ \\
\hline
\end{tabular}


Table 1 cont.: Some of the Modules developed by "Friends with the Universe"

\begin{tabular}{|c|c|c|c|}
\hline No. & Title & Description & Grades \\
\hline$\overline{15}$ & $\begin{array}{l}\text { Alexandrian } \\
\text { Astronomy }^{3}\end{array}$ & $\begin{array}{l}\text { Using a lunar eclipse } \\
\text { and the size of the Earth } \\
\text { to find the size and } \\
\text { distance to the Moon. }\end{array}$ & $12+$ \\
\hline 16 & $\begin{array}{l}\text { How big is } \\
\text { the Earth? }\end{array}$ & $\begin{array}{l}\text { Using the method of } \\
\text { Eratosthenes to find } \\
\text { the size of the Earth }\end{array}$ & $10-12$ \\
\hline 17 & Eclipses & $\begin{array}{l}\text { What causes them and } \\
\text { how can they be observed }\end{array}$ & all ages \\
\hline 18 & Seasons & $\begin{array}{l}\text { By making two simple models } \\
\text { learners discover what really } \\
\text { causes the seasons, if there } \\
\text { are any, and what is the } \\
\text { meaning of the solstices } \\
\text { and equinoxes }\end{array}$ & $8-12$ \\
\hline 19 & $\begin{array}{l}\text { Patterns in } \\
\text { the sky }\end{array}$ & $\begin{array}{l}\text { What are the } \\
\text { constellations and where to } \\
\text { find them by making a } \\
\text { planisphere }\end{array}$ & $6-12+$ \\
\hline 20 & $\begin{array}{l}\text { Making a } \\
\text { spectroscope }\end{array}$ & $\begin{array}{l}\text { Using a small piece } \\
\text { of diffraction grating } \\
\text { and some cardboard, learners } \\
\text { make a spectroscope to } \\
\text { measure to within } 5 \mathrm{~nm} \text {, } \\
\text { cost U.S. } \$ 0.20 \text {. }\end{array}$ & $12+$ \\
\hline 21 & $\begin{array}{l}\text { Using a } \\
\text { spectroscope }\end{array}$ & $\begin{array}{l}\text { Demonstrates the use of } \\
20 \text { above, including the } \\
\text { Doppler effect }\end{array}$ & $12+$ \\
\hline 22 & Making Craters & $\begin{array}{l}\text { What causes craters and } \\
\text { how are they formed }\end{array}$ & $6-10$ \\
\hline 23 & Planning trips & $\begin{array}{l}\text { A skills development exercise } \\
\text { - using assorted timetables } \\
\text { learners are expected to } \\
\text { plan a trip }\end{array}$ & $8-12$ \\
\hline 24 & $\begin{array}{l}\text { Talking to } \\
\text { Mars }\end{array}$ & $\begin{array}{l}\text { An exercise demonstrating } \\
\text { how time delays occur and } \\
\text { what effect they have }\end{array}$ & $6-9$ \\
\hline 25 & Timelines & $\begin{array}{l}\text { Learners use the launching } \\
\text { of satellites as basis for } \\
\text { a timeline in the classroom. } \\
\text { This runs in parallel with } \\
\text { another showing birthdays, } \\
\text { news items of the year }\end{array}$ & $4-8$ \\
\hline
\end{tabular}

${ }^{3}$ See Rijsdijk, 1999. 
local star-lore and in particular the two forthcoming eclipses are seen as invaluable resources to educate many people using newspapers, TV and radio. In the past both solar and lunar eclipses have been used. The forthcoming eclipses in the sub-continent are particularly important and appropriate resources are under development. The logistical problems of tackling large, sparsely populated areas is being researched and addressed.

\subsection{Workshops}

Typically these cater for around 25 learners/teachers at a time, although teacher groups are usually smaller. Workshops for teachers last for about 2 hours, take place after school hours and are frequently interspersed with associated activities such as slide/video shows, a look at the Sun/Moon or other related demonstrations. Workshops for learners are shorter, usually occur during school time or vacation time and are planned as a package accommodating the needs of the teacher.

No special facilities are required: at the SAAO an old store-room has been converted to accommodate these workshops. This was deliberately done to show teachers what can be achieved with minimum of facilities. Everything required for the workshop is supplied: scissors, glue, paper, writing equipment, staplers etc. The reason being that then everyone starts off with the same and the correct stuff!

During the workshop participants are encouraged to help each other for a variety of reasons: the main one being in that it gives those "helping" a chance to build confidence, and frequently language problems are overcome this way. The facilitator often does not have a good enough (if any!) knowledge of the languages used by participants.

One thing that is not tolerated is for workshop facilitators to become surrogate teachers. Frequently teachers who bring classes to the Science Education Resources Centre are under the impression that these workshops are designed to give them a break from teaching! Facilitators should involve them from the outset, and when arranging these workshops for learners this should be made clear.

\subsection{Starbus}

One of the stated objectives of "Friends with the Universe" during YEAST was to reach the rural youth and teachers, (Rijsdijk, 1997). It was obvious that the distances and costs involved made it impossible for these people to travel to major population centres. It was decided instead to take the resources, workshops, demonstrations and talks to the people.

To achieve this a mini-bus was bought, decorated and equipped with all the same equipment and resources as the Science Education Resources Centre and taken into the rural communities. This proved most successful and became known as the Starbus, (Rijsdijk, 1998, 2000). Usually the Starbus would visit a school and use that as a "base": with teachers from surrounding schools coming there to attend the workshops. The "base school" would be carefully selected to maximize the impact of the Starbus visit. 


\section{New Strategies}

In order to find solutions to these problems, the government and a wide range of other organizations have developed and have begun to implement many new strategies.

\subsection{Curriculum 2005}

In 1997, the new curriculum was finalized. Called Curriculum 2005: (Department of Education, 1997) it is an Outcomes Based Education (OBE) system, loosely based on that of New Zealand, Holland and Canada. It has done away with traditional subjects and replaced them with eight Learning Areas. One of which, the Natural Sciences, is broken into four themes or strands: Life and Living, Matter and Materials, Energy and Change and Earth and Beyond. Astronomy now features as a substantial part of the latter.

Implementation started in 1998 but the new curriculum was soon found to be too cumbersome and too far removed from the traditional system. The language was difficult, the structure too theoretical and it was generally beyond the scope of many teachers. Training courses took time and at the end teachers were often confused and had little knowledge of what actually to do in the classroom. It has been reviewed (Chisholm, 2000), and many of the complexities have been removed: implementation is expected to proceed more smoothly after June 2001 when the revised C2005 will be introduced.

\subsection{Tirisano}

A word meaning "working together". The plan was implemented by the South African government in 1999 (Department of Education, 1999) with the aim of building an education and training system for the 21st century. Its main goals are:

- breaking the back of illiteracy within five years,

- developing schools as centres of the community,

- developing the professional quality of teachers,

- developing a life-long learning process, and

- combating HIV/AIDS through education.

This is a new programme and there is as yet no evaluation of its success and it will be some time before any statistics become available. There is also an active advisory panel to advise the minister of education on new strategies by consulting with a broad spectrum of science, technology and education experts, giving the minister a clear indication of the country's needs, (Kahn, 2000).

\subsection{Other Outreach Programmes}

From an astronomical point of view, all other facilities involved with astronomy run some sort of outreach, education and popularization programmes. The national radio astronomy facility at Hartebeesthoek (HartRAO) in Gauteng is 
very active and runs many programmes similar to those of the SAAO. When the occasion arises, such as at the National Science Festival, SASOL SciFest, SAAO and HartRAO run joint workshops.

Boyden Observatory, near Bloemfontein, in the Free State is becoming active again and is run by Free State University. They run an education programme using some SAAO resources and also have many open nights. The planetaria in Cape Town and Johannesburg are kept busy and they too are active in educational outreach. The Cape Town planetarium offers an introductory course on descriptive astronomy twice a year and consists of five, two hour lectures.

Over the last few years a few large science centres have started up and there are also many smaller ones scattered around the country. They have formed an umbrella organization known as the South African Association of Science and Technology Centres, (SAASTEC). One on the north of Kwazulu-Natal is particularly active and runs practical science classes for over 6000 final year grade 12 learners a year!

\section{Universities}

The university with the most accessible course in astronomy is the University of South Africa (UNISA). This is a distance-learning university and due to a rationalization process that is being implemented in the country, it is now the only one to offer a full undergraduate course.

The University of Cape Town has close links with SAAO and post graduate students studying for M.Sc. and Ph.D degrees would be jointly supervised by staff from both institutions. Witwatersrand, Natal (Durban and Pietermaritzburg) and Pothchefstroom all offer some tuition in astronomy, whilst Rhodes University specializes in radio-astronomy.

As is apparently the case in other parts of the world, the number of students studying physics is decreasing and several universities are considering combining physics with astronomy and space science. At present the council for higher education is reviewing faculties at universities and technikons throughout the country, and at this time there is no clarity yet: it may well be that there will be some rationalization and that only certain universities will be offering astronomy as an undergraduate and post-graduate course.

\section{The Future}

When looking at the needs of South Africa in the future there is no doubt that research will have to be relevant and that it should address the social, economic, educational and political needs of the country, (Medupe and Kaunda, 1997). The government has however realized that there is also a need for the people within country and the rest of the world not see South Africa as just another Third-World nation (DACST 1996):

Scientific endeavour is not purely utilitarian in its objectives and has important associated cultural and social values. It is also important to maintain a basic competence in "flagship" sciences such as physics and astronomy for cultural reasons. Not to offer them would be to 
take a negative view of our future - the view that we are a secondclass nation, chained forever to the treadmill of feeding and clothing ourselves.

There is a need to establish some self-esteem, especially amongst the country's youth. In the past learners were taught a range of myths and legends about astronomy. They were taught how science changed the perception of the universe in which we lived by describing theories of the universe of the ancient Greek, Roman, Babylonian, Aztec, Mayan and many other cultures, but never any of their own, the theories of the San, Batswanas, Zulus and Xhosas were ignored: science was a white man's thing, (Medupe and Kaunda, 1997).

There is a rich heritage of ethno-astronomy in Southern Africa: it is an oral tradition, but this makes it no less relevant to the people of the region. In the past, as in a large number of other cultures, many aspects of life were controlled by the stars. The time to plant, initiation ceremonies and other festivals were determined by the rising and setting of identifiable single stars, groups of stars or constellations. What in the West are called the Pleiades or the Seven Sisters, are known as "isiLemela" to many people in South Africa: they are the Digging Stars, their rising early in the morning meant it was the time to start preparing the soil for planting. Similarly, there are indigenous names for many other stars and constellations, (Snedegar, 1995).

This rich heritage should be used to make South-African education more relevant to its own people: intellectual and cultural enslavement is as bad as economic, physical or political enslavement. Indigenous knowledge is slowly coming to the fore: there is an indigenous culture of science and as Walter Massey, former director of the U.S. National Science Foundation said, "Science provides a set of common experiences, a kind of cultural glue to hold together multicultural societies."

The Southern African Large Telescope (SALT) should, and will, become an icon for South African youth: physical evidence that science is not something that happens only in Europe, Japan and the United States of America; it happens in South Africa as well! A workshop is planned for 2001 in Cape Town where the educational potential of all the large telescopes in the world, optical and radio, will be discussed to see if there is a possible synergy. For the country's youth to see that South Africa is a part of international big science is as important as, no, more imoprtant than, that same youth seeing the national football side taking part in the world cup.

It is the Southern, not South-African Large Telescope, this subtle difference clearly indicates that it will provide an access to the skies for the scientific and astronomical community, not only of South Africa, but of the sub-continent as a whole. Together with the telescope is a Collateral Benefits Plan which clearly sets out the role that SALT will play in the larger community, it will:
A. support industrial empowerment,
B. provide educational empowerment,
C. enhance Public Outreach and provide direct educational benefits,
D. develop a visitor centre, 


\section{E. be an African facility.}

"Friends with the Universe" has already started on aspects of $\mathrm{B}$ and $\mathrm{C}$, and SAAO is at present working on developing D: two such centres are envisaged, one in Cape Town and one in Sutherland in the Karoo where the SAAO observing site is located. To be known as Stargates the centres will focus on spectroscopy with an exhibit called "Fingerprinting Light". With construction on SALT starting in 2001 , the Sutherland Stargate is now a priority.

Acknowledgments. I would like to thank Drs Bob Stobie, Patricia Whitelock, and Peter Martinez for their continued support for the educational programme at SAAO and Frank Andrews and Tony Fisher of Carter Observatory, Wellington, New Zealand for encouragement and sharing the wealth of experience in producing material for OBE education. In addition I would like to thank the IAU and the SAAO for funding to attend the 2000 General Assembly.

\section{References}

Arnott, A. and Kubheka, Z. 1996, Access, enrolment and pass rates in mathematics and science at secondary schools. NARSET report: Issues Relating to Access and Retention in Science, Engineering and Technology in Higher Education. FRD, Pretoria.

Blankley, W. 1994, The abyss in African school education in South Africa, S. Afr. J.Sci. 90, 54.

Chisholm, L. 2000, Report of the Review Committee of Curriculum 2005.

Clerk, D. 2000, - Just what is so difficult about the language encountered by first year university students in science courses. An ongoing investigation Physics Conference, Rand Afrikaans University (unpublished).

DACST (Department of Arts Science and Technology) 1996, White Paper on Science and Technology, Preparing for the 21st Century.

Department of Education. 1997, Curriculum 2005 - a discussion document.

Department of Education. 1999, Tirisano: Working Together to Build a South African Education and Training System for the 21st Century. Policy document.

Enderstein, L. G. and Spargo, P. E. 1998. The effect of context, culture and learning on the selection of alternative options in similar situations by South African pupils. Int. J. Sci. Educ. 20, 711 - 736.

Grayson, D. J. 1996, A holistic approach to preparing disadvantaged students to succeed in tertiary science studies. Part I. Design of the Science Foundation Programme. Inter. J. Sci. Educ. 18, 998-1013.

Grayson, D.J. 1997, A holistic approach to preparing disadvantaged students to succeed in tertiary science studies. Part II. Outcomes of the Science Foundation Programme. Inter J. Sci Educ. 19, 107-123.

Kahn, M. 2000, Toward a Strategy for the Development of Science, Mathematics and Technology Education. Working document presented at a Strategic Planning Workshop to advise the Minister of Education, NRF Pretoria. Unpublished. 
Medupe, R. T. and Kaunda, L. 1997, The Problems of Science in Africa, Mercury 26, no. 6 Nov./Dec 1997, 16 - 18.

Percy, J. R. 1999, Effective Learning and Teaching of Astronomy. Teaching of Astronomy in Asia-Pacific Region Bulletin No. 15, 41 - 44.

Rijsdijk, C. L. 1997, Friends with the Universe. Business plan submitted to the Foundation for Research Development, internal document.

Rijsdijk, C. L., 1998. Taking Science to the People. Proceedings of the 2nd National Conference on the Public Understanding of Science and Technology in South Africa: Science and Society, Pretoria.

Rijsdijk, C. L. 1999, Quantum Magazine, NSTA.

Rijsdijk, C. L. 2000. Using Astronomy as a vehicle for Science Education. Combined conference of the Astronomical Society of Australia and the Royal Astronomical Society of New Zealand, Sydney, July, 2000. PASA www.atnf.csiro.au/pasa.

Rutherford, M. 1997, Opening access to quality education. S. Afr. J. Sci. 7, 211-215.

Schneps M. and Sadler, P. M. 1988. A Private Universe (video), Pyramid Films, Santa Monica. CA

Snedegar, K. V. 1995, Vistas in Astronomy

Wesi, R. P., Lemmer, M. and Smit, J. J. A., 2000. Science teachers perceptions of the Universe. Paper delivered at the South African Institute of Physics Conference, Rand Afrikaans University, July, 2000, unpublished.

\section{Discussion}

Fierro asked what kind of follow-up material would be produced for teachers. Rijsdijk replied that very little was produced at present, but he hoped to make use of some of the assessment and follow-up material used by the Carter Observatory in New Zealand. Many teachers return of their own volition and some come back often, bringing new teachers with them. 